GLOBAL WATER PATHOGEN PROJECT

PART ONE. THE HEALTH HAZARDS OF EXCRETA: THEORY AND CONTROL

INTRODUCTION TO THE IMPORTANCE OF SANITATION

\title{
Colleen Naughton
}

University of South Florida

Tampa, United States

\section{James Mihelcic}

University of South Florida

Tampa, United States 


\section{Copyright:}

\section{cc) (1) (2) \\ BY SA}

This publication is available in Open Access under the Attribution-ShareAlike 3.0 IGO (CC-BY-SA 3.0 IGO) license (http://creativecommons.org/licenses/by-sa/3.0/igo). By using the content of this publication, the users accept to be bound by the terms of use of the UNESCO Open Access Repository (http://www.unesco.org/openaccess/terms-use-ccbysa-en).

\section{Disclaimer:}

The designations employed and the presentation of material throughout this publication do not imply the expression of any opinion whatsoever on the part of UNESCO concerning the legal status of any country, territory, city or area or of its authorities, or concerning the delimitation of its frontiers or boundaries. The ideas and opinions expressed in this publication are those of the authors; they are not necessarily those of UNESCO and do not commit the Organization.

\section{Citation:}

Naughton, C. and Mihelcic, J.R. 2017. Introduction to the Importance of Sanitation. In: J.B. Rose and B. Jiménez-Cisneros, (eds) Water and Sanitation for the 21st Century: Health and Microbiological Aspects of Excreta and Wastewater Management (Global Water Pathogen Project). (J.B. Rose and B. JiménezCisneros) (eds) Part 1: The Health Hazards of Excreta: Theory and Control), Michigan State University, E. Lansing, MI, UNESCO. https://doi.org/10.14321/waterpathogens.1

Acknowledgements: K.R.L. Young, Project Design editor;

Website Design: Agroknow (http://www.agroknow.com).

Last published: September 20, 2017 


\section{Summary}

Globally, 946 million people still open defecate (9 out of 10 live in rural areas), 2.4 billion people lack access to basic sanitation ( 7 out of 10 in rural areas), 663 million lack access to basic water sources, and diarrhea is the second leading cause of death in children under five much of which is preventable by clean water and sanitation (WHO/UNICEF JMP, 2015; WHO, 2017). Sanitation is one of the most important aspects of community well-being because it protects human health, extends life spans, and is documented to provide benefits to the economy. Sanitation (e.g. toilets, latrines, mechanized wastewater treatment) is currently deployed as a way to contain and/or treat human excreta (and in some cases grey water) to protect human health and the environment including water bodies that are sources for drinking water. Therefore the 2015 United Nation's (UN) Sustainable Development Goal (SDG) 6 for 2030 aims to achieve equitable access to safely managed water and adequate sanitation for all and end open defecation. Achieving universal and equitable sanitation for all will require access to information and data on pathogens and sanitation technologies and a network of community members, professionals, and experts who reside all over the world like the Global Water Pathogens Project. Accordingly, this chapter provides important context and an introduction to the importance of sanitation and includes sections on:

- Global Sanitation - Statistics and International Goals

- The Relationship between Sanitation and Disease

- Quantifying Health Impacts of Disease: HALYs (Heath Adjusted Life Years), Quality Adjusted Life Years (QALYS) and Disability Adjusted Life Years (DALYS)

- The Economic Value of Sanitation

- Appropriate and Low-Cost Sanitation

- Potential of Resource Recovery and Reuse that is Linked to Safe Sanitation

\subsection{Overview}

Sanitation is one of the most important aspects of community well-being because it protects human health, extends life spans, and is documented to provide benefits to the economy. Sanitation (e.g. toilets, latrines, mechanized wastewater treatment) is currently deployed as a way to contain and/or treat human excreta (and in some cases grey water) to protect human health and the environment. "Improved" (now referred to as "basic" since 2015) access to sanitation is defined by the Joint Monitoring Programme (JMP) as one that separates "human excreta from human contact" in a hygienic manner (e.g. flush toilet, ventilated improved pit latrine (VIP), piped sewer systems, composting toilets, and septic systems) (WHO/UNICEF JMP, 2017). Examples of unimproved sanitation are: pit latrines without a slab and bucket or hanging latrines. Basic sanitation facilities are defined as being used by only one household and may empty on-site or are connected to a sewer system that may or may not be followed by treatment. Many sanitation facilities are however shared in both urban and rural settings. The JMP reports the level of sharing can vary considerably and has considered setting a upper threshold of five households that could share an improved facility and still be considered covered by basic sanitation. However, there is no consensus if sharing a basic sanitation facility results in improved or lessened health.

One key goal of sanitation is to safely reduce human exposure to pathogens. Pathogens are excreted by infected individuals and if not properly contained or treated, may present a risk to humans who come in contact with them. These individuals can also be exposed to pathogens through drinking water or eating food contaminated with pathogens found in human excreta. Similarly, the JMP has specified that safely managed drinking water must be free from fecal contamination (WHO, 2017).

The Global Water Pathogen Project (GWPP) was launched because of the need to update the highly referenced and valuable reference book "Sanitation and Disease: Health Aspects of Excreta and Wastewater Management"(Feachem et al., 1983). A similar valuable companion book is "Appropriate Technology for Water Supply and Sanitation: Health Aspects of Excreta and Sullage Management - A State-of-the-Art Review" (Feachem et al., 1981). Two key features of Feachem et al. $(1981,1983)$ are that they provide detailed information on disease causing pathogens associated with human excreta and also the performance of specific sanitation technologies and management strategies in inactivating pathogens. These books have been widely used by educators, researchers, and practitioners for over 35 years. The preface of Feachem et al. (1983) cited a 1975 statistic from the World Health Organization (WHO) that: “...75\% of urban dwellers did not have sewerage.... and $25 \%$ had no disposal system of any kind. In rural areas, 85\% lacked any adequate excreta disposal facility." Feachem et al. (1983) called for "major national and international initiatives" if any "substantial improvement in sanitation systems in the developing world is to be made in the next few decades" (Feachem et al., 1983). Several decades later there have been many national and global initiatives to reduce the number of people in the world without access to basic sanitation. Unfortunately, 2.4 billion people still lack access to adequate sanitation including $50 \%$ of people in rural areas (WHO/UNICEF JMP, 2015). Because of these disparities, diarrheal disease is still a major cause of death in children under five and also for Disability Adjusted Life Years (DALYs) in the developing world (WHO, 2016). In fact, the overall disease burden associated with lack of sanitation in low and middle income countries in 2012 was estimated to be 280,000 diarrhea deaths per year (compared to estimates of 502,000 diarrhea deaths due to inadequate drinking water and 297,000 diarrhea deaths from lack of hand hygiene) (Prüss-Üstün et al., 2014).

Population growth, aging infrastructure, and water scarcity that are all exacerbated by climate change in some locations, present challenges to achieve the United Nation's Sustainable Development Goal (SDG) 6 (Targets 6.1 and 6.2 ) to provide access to safe water and sanitation for all by 2030. Even if access to "basic" water and sanitation is 
achieved for all by 2030 (see Figure 1), SDG 6 will not be achieved as this must include safely managed drinking water and wastewater treatment (e.g., Target 6.3) (WHO, 2017). For example, currently only a small percentage of wastewater that is collected is then sent to a well-designed and managed treatment plant. The rest may be only partially treated or directly discharged into the environment without any treatment. In fact, some $85-95 \%$ of collected wastewater is now discharged to the environment without treatment in developing countries, contaminating many waterways that impacts human health and the environment (WWDR, 2017). This is a reason why Target 6.3 for SDG 6 includes language to halve the proportion of untreated wastewater. Reducing discharge of untreated wastewater to the environment is also economically important because of the large number of people in the world who depend on water quality for their livelihood and well-being (e.g. fishers and farmers). Importantly, as discussed in a later section, provision of basic sanitation by 2030 should be integrated with innovative sanitation solutions that incorporate safe and fitfor-purpose recovery of valuable resources (e.g. water, energy, nutrients, and chemicals) but still prevents exposure to pathogens over the complete sanitation chain. Provision of basic sanitation may also protect people from adverse health effects associated with outcomes of climate change such as increases in temperature and rainfall intensity (Levy et al., 2016; Mellor et al., 2016).

Achieving universal and equitable sanitation for all will require access to information and data on pathogens and sanitation technologies and a network of community members, professionals, and experts who reside all over the world. Accordingly, this chapter provides an introduction to the importance of sanitation and includes sections on:

- Global Sanitation - Statistics and International Goals

- The Relationship between Sanitation and Disease

- Quantifying Health Impacts of Disease: HALYs (Heath Adjusted Life Years), Quality Adjusted Life Years (QALYS) and Disability Adjusted Life Years (DALYS)

- The Economic Value of Sanitation

- Appropriate and Low-Cost Sanitation

- Potential of Resource Recovery and Reuse that is Linked to Safe Sanitation

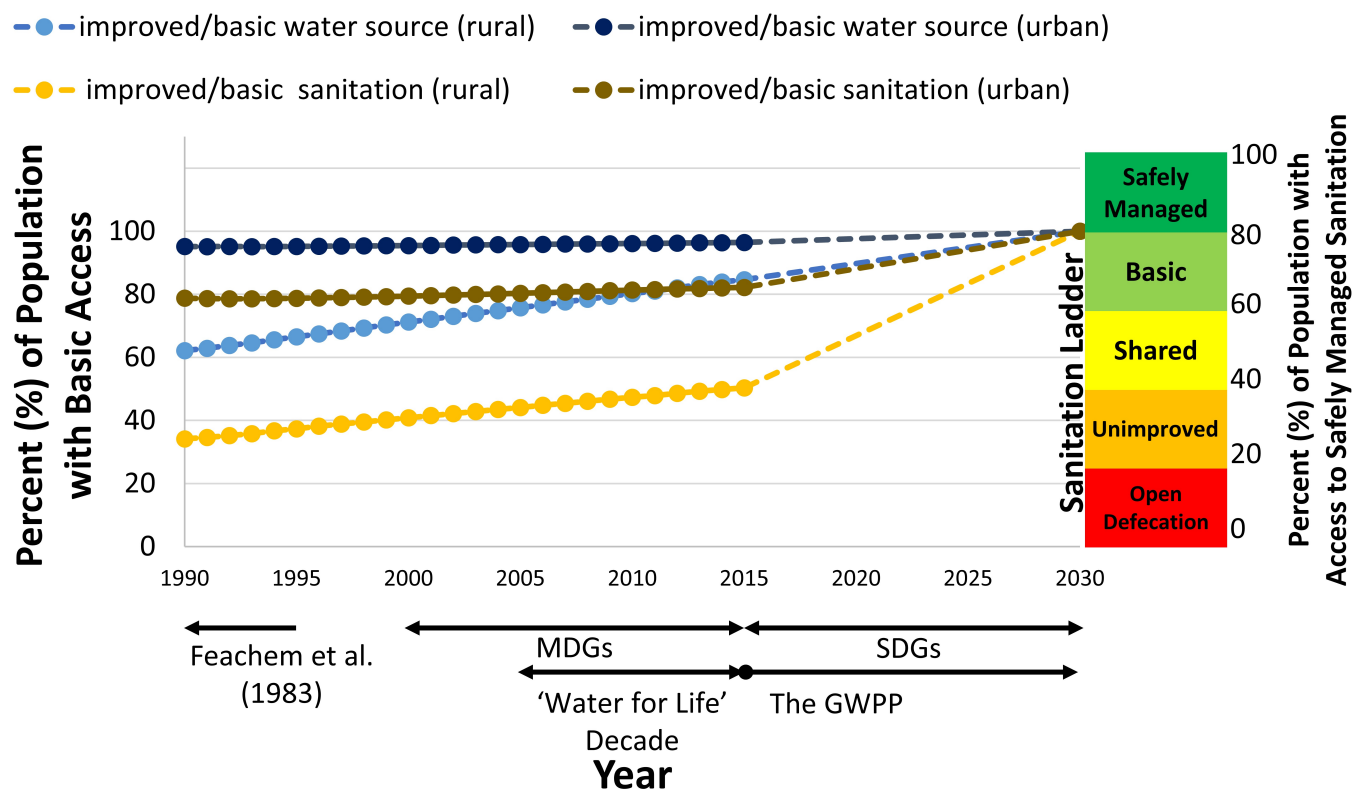

Figure 1. Percentage of rural and urban populations with access to improved/basic water ${ }^{1}$ or sanitation $^{2}$ between 1990-2015 compared to the United Nation's (UN) Sustainable Development Goals (SDGs) sanitation ladder (on right side) (WHO/UNICEF JMP, 2017) in relation to other international initiatives such as the UN's Millennium Development Goals (MDGs) and 'Water for Life' Decade and the Global Water Pathogen's Project (GWPP) (figure generated with data from the WHO/UNICEF JMP (2015)).

${ }^{11}$ "Improved", now "basic", access to water is defined by the Joint Monitoring Programme (JMP) as a source that is protected from external contamination, notably human excreta (e.g. piped water at household or to public tap, a borehole, a protected spring, and rainwater collection systems). Examples of unimproved sources are: tank truck, or bottled water and unprotected wells and springs.

"Improved", now "basic", access to sanitation is defined by the JMP as one that separates "human excreta from human contact" in a hygienic manner that are not shared with other households (e.g. flush toilet, ventilated improved pit latrine (VIP), piped sewer systems, composting toilets, and septic systems). Examples of unimproved sanitation are: pit latrines without a slab, bucket or hanging latrines.

"Safely managed" access to sanitation are basic facilities that dispose and/or treat human excreta on or off site safely. The "safely managed" sanitation category was added to the previous MDG ladder to ensure that collected wastewater was treated prior to discharge or reuse. 


\subsection{Global Sanitation - Statistics and International Goals}

In the past few decades, great progress has been made in achieving the United Nation's Millennium Development Goal (MDG) to provide access to sanitation where 2.1 billion have gained access to improved/basic sanitation from 1990 levels (WHO/UNICEF JMP, 2015). Yet, globally, 946 million people still open defecate (9 out of 10 live in rural areas), 2.4 billion people lack access to basic sanitation (7 out of 10 in rural areas), 663 million lack access to basic water sources, and diarrhea is the second leading cause of death in children under five much of which is preventable by clean water and sanitation (WHO/UNICEF JMP, 2015; WHO, 2017). Therefore the 2015 United Nation's (UN) Sustainable Development Goal (SDG) 6 for 2030 aims to achieve equitable access to safely managed water and adequate sanitation for all and end open defecation. Nevertheless, SDG 6 has not been the first time that the world has aimed to achieve access to water and sanitation for everyone. For example, the International Decade for Clean Drinking Water (1981-1990) made and fell short of this target (GRDC, 2017). Later, the international community aimed through the MDG 7 for
Environmental Sustainability in 2000 to halve those that did not have access to improved (now basic) water sources and sanitation in 1990 by 2015 (MDG Target 7c) (United Nations, 2015).

During the MDG period, there were a number of other important international initiatives and declarations. The UN declared 2005-2015 the International Decade for 'Water for Life' to promote international commitments to water and sanitation (Water for Life, 2015). Also, the international year of sanitation was declared in 2008 to raise awareness and accelerate progress towards MDG Target 7c (IYS, 2007). Notably in 2010, access to water and sanitation was officially recognized as a human right by the UN General Assembly in Resolution 64/292 (United Nations, 2010). In 2013, the Deputy Secretary General of the UN launched a call to action to end open defecation by 2025 (WHO/UNICEF JMP, 2015). Overall, in 2015, MDG Target 7c was achieved for access to improved/basic water sources. Unfortunately, even with the successes mentioned previously, the world fell short of halving those without access to improved/basic sanitation by 700 million people particularly in Asia and sub-Saharan Africa (WHO/UNICEF JMP, 2015).

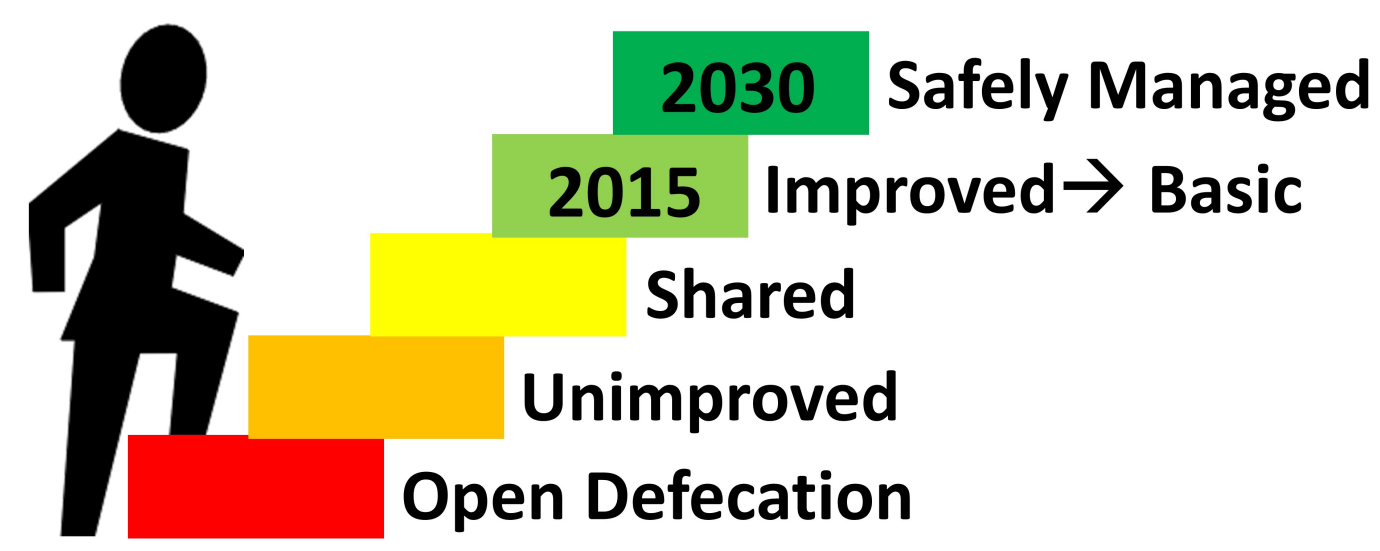

Figure 2. United Nation's Sustainable Development Goal (SDG) sanitation ladder (2015-2030) that adds “safely managed" ${ }^{2}$ and "shared" categories, and changes "improved" to "basic"1 from the previous Millennium Development Goal (MDG) sanitation ladder (2000-2015) (WHO/UNICEF JMP, 2015, 2017).

\begin{abstract}
"Improved", now "basic", access to sanitation is defined by the JMP as one that separates "human excreta from human contact" in a hygienic manner that are not shared with other households (e.g. flush toilet, ventilated improved pit latrine (VIP), piped sewer systems, composting toilets, and septic systems). Examples of unimproved sanitation are: pit latrines without a slab, bucket or hanging latrines.
\end{abstract}

2 "Safely managed" access to sanitation are basic facilities that dispose and/or treat human excreta on or off site safely.

With the adoption of the SDGs in 2015, SDG 6 aims to achieve universal and equitable access (e.g. rural and urban, and men and women) to sanitation by 2030 and also halve the amount of collected wastewater that goes untreated which is an estimated $80 \%$ worldwide (WWDR,
2017). Thus, a "safely managed" sanitation category has been added to the previous MDG ladder (see Figure 2). Furthermore, universal access not only applies to the household level but also to health centers, schools, and workplaces (WHO/UNICEF JMP, 2017).

There are 17 SDGs and SDG 6 is integral to achieve the others (Zhang et al., 2016) particularly human health (SDG 3) and economic growth and employment (SDG 8) that will be discussed later in the "Sanitation and Disease" and the "Economic Value of Sanitation" sections of this chapter. Figure 3 provides a systems diagram that shows this interconnectedness of SDG 6 related to sanitation with the other sixteen SDGs (Zhang et al., 2016). The relation between SDG 6 and women's equality and empowerment (SDG 5) is also further discussed in the GWPP introductory chapter on Gender and Sanitation Issues. 


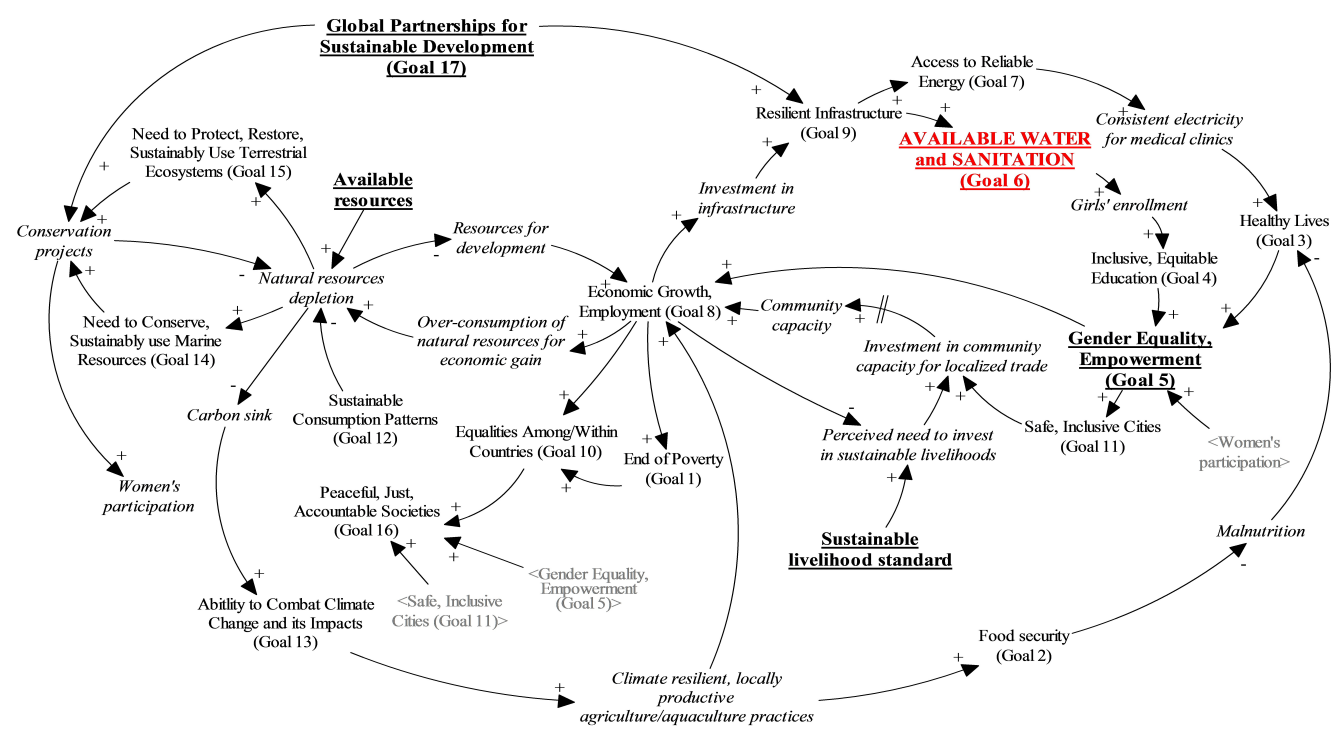

Figure 3. Conceptual systems model of the Sustainable Development Goals and their interconnections (reprinted with permission from "More than Target 6.3: A Systems Approach to Rethinking Sustainable Development Goals in a Resource-Scare World" (Zhang et al., 2016) under the terms of the Creative Commons Attribution License).

A large challenge to achieving the SDGs is whether universal and equitable water and sanitation for all is achievable by 2030. This is because the international community has fallen short of these targets before and noted challenges from climate change and rising population, particularly in urban areas. According to UN DESA (2011), the world population is expected to increase from 7 billion in 2011 to 9.4 billion in 2050. This population increase includes a doubling of urban populations from 3.6 billion to 6.3 billion for the same period and a quadrupling of the African population. Natural disasters are projected to increase in frequency and intensity as a result of climate change of which $90 \%$ are water-related (UNESCAP, 2015). Based on Figure 1, the rates to achieve access to basic water sources are on track but rates to achieve basic sanitation in rural and urban areas will require a significant acceleration and investment by local and global communities (as shown by the steep increase required after year 2015). Breaking down the percentages from Figure 1 according to region and income category (shown in Figure 4) show some of the challenging areas to meet global sanitation targets, particularly for the Least Developed Countries (LDCs) and sub-Saharan Africa and Asia. 

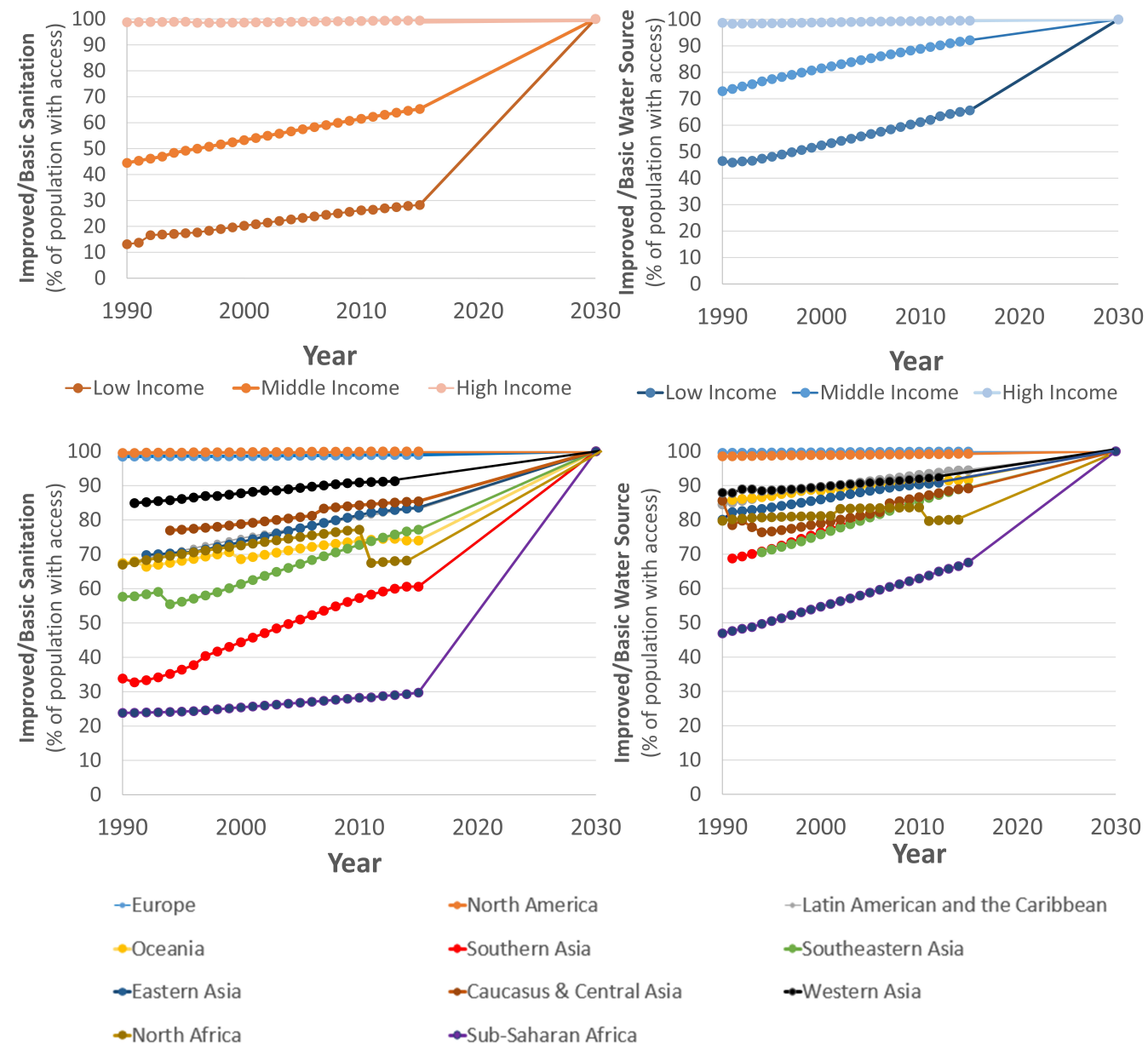

Figure 4. Percentage of different income and regional populations with access to improved/basic water ${ }^{1}$ (right) and sanitation $^{2}$ (left) between 1990-2015 and the 2030 target of $100 \%$ access for the United Nation's (UN) Sustainable Development Goals (SDGs) (figure generated with data from the WHO/UNICEF JMP (2015)).

"Improved", now "basic", access to water is defined by the Joint Monitoring Programme (JMP) as a source that is protected from external contamination, notably human excreta (e.g. piped water at household or to public tap, a borehole, a protected spring, and rainwater collection systems). Examples of unimproved sources are: tank truck, or bottled water and unprotected wells and springs.

"Improved", now "basic", access to sanitation is defined by the JMP as one that separates "human excreta from human contact" in a hygienic manner that are not shared with other households (e.g. flush toilet, ventilated improved pit latrine (VIP), piped sewer systems, composting toilets, and septic systems). Examples of unimproved sanitation are: pit latrines without a slab, bucket or hanging latrines.

Furthermore, pathogen pollution is documented to contaminate one third of the rivers in Africa, Asia and Latin America (UNEP, 2016). That is why SDG 6.3 aims to halve the proportion of collected wastewater that goes untreated. However, this will require a large amount of capital for design, construction, and operation of treatment and/or resource recovery technologies and systems particularly in urban areas and informal settlements. Additionally, there is a serious lack of data on what the current baseline is even to achieve SDG 6.3. For example, Sato et al. (2013) reported that only 55 of 181 countries had sufficient data even on the volume of wastewater generated and type of treatment used. Moreover, much of the investment in water and sanitation has only been made in physical infrastructure but not as much in maintenance and human resources (UN-Water, 2015). In fact, out of 67 countries, less than $20 \%$ reported to the Global Assessment of Sanitation and Drinking-Water (GLAAS) that they had sufficient skilled labor and technicians to support provision of rural sanitation (WHO, 2014). Therefore, while access to basic sanitation may be achieved by 2030 , there will be much work left after the SDGs to ensure Target 6.3 is met in regards to increasing the percentage of wastewater that is treated or safely reused.

\subsection{The Relationship between Sanitation and Disease}

The importance of sanitation to community well-being has been known for thousands of years. For example, there is archaeological evidence of latrines, cesspits, and/or drainage channels discovered from the Mesopotamian Empire (currently Iraq), Scotland (3200 B.C.), ancient Greece (3000 B.C.), China (2500 B.C.), and Egypt (2100 B.C.) (Bond et al., 2013). However, the relationship 
between sanitation and disease did not receive worldwide adoption and promotion until the 1800s with the Sanitary "Awakening"/ "Revolution". Although many cities had used toilets and sewer systems, they were much like those in many parts of the world today where the wastewater goes untreated. This in turn can spread disease and lead to environmental degradation. Evidence of harmful parasites and pathogens like whipworm (Trichuris trichiura), roundworm (Ascaris lumbricoies) and dysentery (Entamoeba histolytic) have also been discovered in ancient toilets and other waste disposal sites (Mitchell, 2017).

A notable turning point for understanding the connection between sanitation and disease was the 1854 cholera epidemic in London. At that time, Dr. John Snow and Henry Whitehead discovered through mapping how cholera was spread in contaminated water because those falling ill used a specific pump for their drinking water (Johnson, 2006). Much of the water supply in London at the time was contaminated by human feces. In the later 1800s, Edwin Chadwick promoted sewage disposal and running water in homes in the United Kingdom (U.K.) (Ferriman, 2007) which was the time that the "Great Sanitary Awakening" began in the U.S. and U.K (Mihelcic et al., 2017). The sanitary revolution/awakening was in fact selected as the top medical advance since 1840 by over 11,300 readers of the British Medical Journal (Ferriman, 2007). This period was also the origin of the discipline of sanitary engineering (also referred to as environmental engineering and environmental health engineering) (Mihelcic et al., 2017). Nevertheless, many of the sewer systems constructed during the Great Sanitary Awakening did not provide treatment of the wastewater or address rural sanitation issues. This resulted in the continued spread of disease and environmental pollution.

Another major milestone related to the connection between sanitation and disease occurred in 1958, when engineers Edmund Wagner and J.N. Lanoix published a monograph for the World Health Organization entitled "Excreta Disposal for Rural Areas and Small Communities" that included the widely-known F-diagram (see an adaptation in Figure 5). The F-diagram clearly depicts how a new host (the mouth) may be infected by fecal matter (and thus associated pathogens) through different routes of exposure that engage fingers, flies, food, fields, and fluids. The F-diagram depicted in Figure 5 also shows the relationship between sanitation and disease where sanitation technologies such as latrines can act as barriers against several different routes of pathogen exposure.

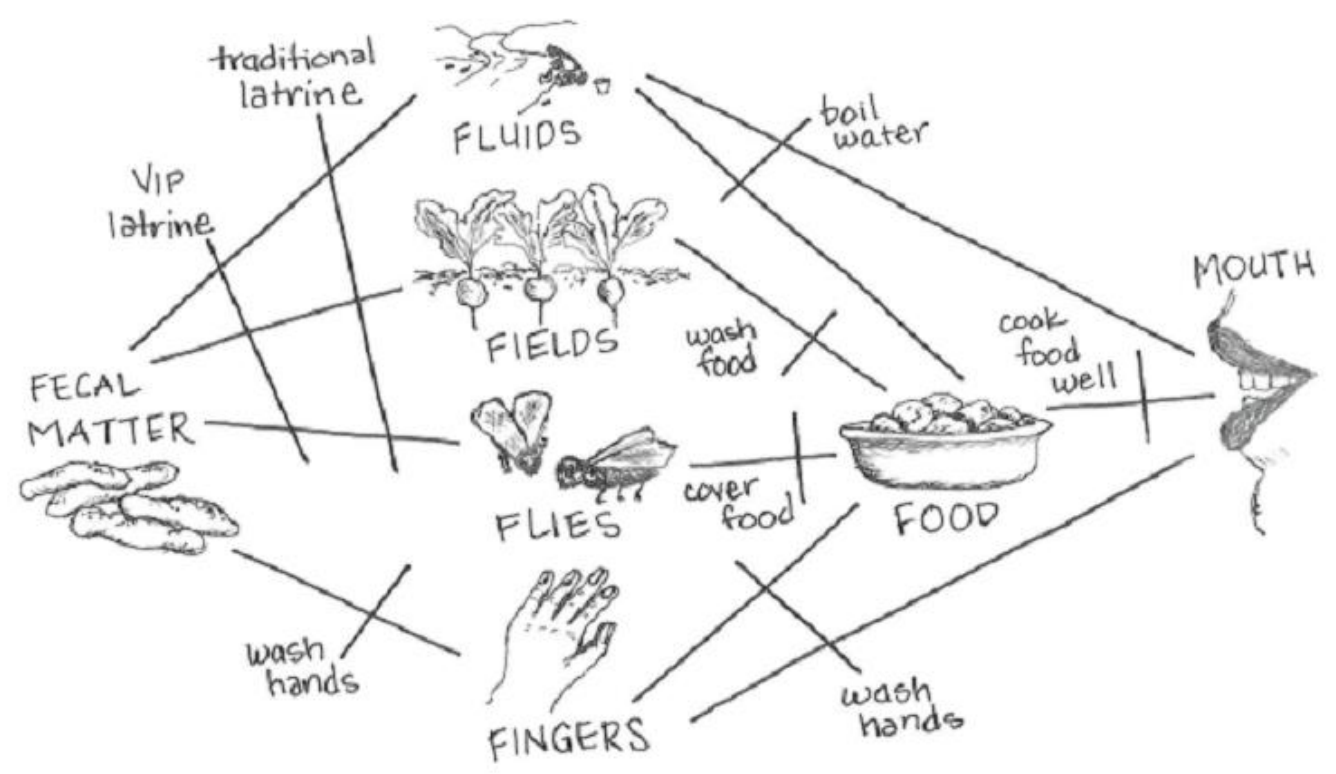

Figure 5. The "F-Diagram" of Fecal-oral transmission from contaminated fluids (water), fields, flies, food, and fingers (Reproduced from Mihelcic et al. (2009) with permission from ASCE; artwork by Linda Phillips.). Transmission routes can be blocked from basic sanitation infrastructures (e.g., VIP and traditional latrines), safe water management, and hygiene interventions such as washing hands.

Recent systematic reviews found that most studies determined a $30-40 \%$ reduction in diarrheal disease from sanitation (Wolf et al., 2014) and lower likelihood of infection with soil-transmitted helminths (Strunz et al., 2014). Providing sanitation may also reduce malnutrition, stunting and cognitive development (Guerrant et al., 2013) but most studies have focused on impacts on diarrheal disease for children under five. However, recent scientific literature has drawn attention to the methodological inadequacies of these studies and the challenges in connecting sanitation interventions to health improvements. Unlike, handwashing interventions, it is more difficult and expensive to conduct large, randomized control trials of sanitation interventions (Schmidt, 2014). This is because of both the larger cost of sanitation infrastructure compared to handwashing and longer project timelines. One of the only and largest randomized controlled trials for sanitation was conducted in rural India where 50 villages received a latrine intervention and construction project and 50 villages received no 
intervention (Clasen et al., 2014). While latrine coverage increased considerably in the intervention villages ( $9 \%$ to $63 \%$ ) compared to the control villages ( $8 \%$ to $12 \%$ ), there was no statistically significant difference in diarrheal disease prevalence, soil-transmitted helminth infection, or child malnutrition. Clasen et al. (2014) proposed that there were not clear health differences because over a third of households in the intervention communities did not have a latrine. Households without latrines may still contaminate the surrounding environment and water sources that have adverse health impacts on households in the same community with latrines (Harris et al., 2017). Moreover, presence of a latrine does not necessarily indicate use as other household members may still open defecate particularly children. Furthermore, improper design and placement of sanitation without proper fecal sludge management or wastewater treatment may contaminate the local environment and decrease water quality (WWDR, 2017). For example, pit latrines, particularly those built where there are shallow groundwater tables or near water sources, may cause fecal and nitrate pollution in water bodies and aquifers (Graham and Polizzotto, 2013). Overall, decreased disease incidence will depend on a combination of sanitation, hygiene, water, and waste management improvements and effective behavior change.

\subsection{Quantifying Health Impacts of Disease: HALYs (Health-adjusted life years), QALYS (Quality-adjusted life years), and DALYs (Disability-adjusted life years)}

Health measurement methods are necessary to quantify health, disease, and disability among different population groups (e.g., regions, income-level, gender, countries) to prioritize interventions and determine their economic value. There are two types of population health measurements referred to as health-adjusted life years (HALYs). HALYs combine death and morbidity impacts by two methods: (1) quality-adjusted life years (QALY) and (2) disability-adjusted life years (DALY) (see Table 1 for definitions). Both QALYs and DALYs have their advantages, biases, and limitations. DALYs have been primarily used instead of QALYs by international organizations like the World Health Organization (WHO), World Bank, and United Nations to estimate the global burden of disease. However, there is a need to improve and better integrate both QALYs and DALYs to estimate and design health interventions more equitably and ethically. 
Table 1. Definitions of HALY (Health-adjusted life years), QALY (Quality-adjusted life years), and DALY (Disability-adjusted life years)

\section{HALY (Health-adjusted life years)- summary of population health measurements that combines death and morbidity impacts. Two types of HALYs are the QALY and the DALY:}

QALY

(Qualityadjusted life years)
A health measure that incorporates quality of life and life expectancy based on average samples of health ratings from groups of people and/or professionals. One year in full or perfect health is equal to one QALY. Health-related quality of life (HRQL) is plotted on a scale of 0 (death) to 1 (full health) (see diagram below). The QALY was developed primarily for cost-effective analysis (CEA) in the late 1960s to determine the effectiveness of different medical treatments, technologies, and interventions.

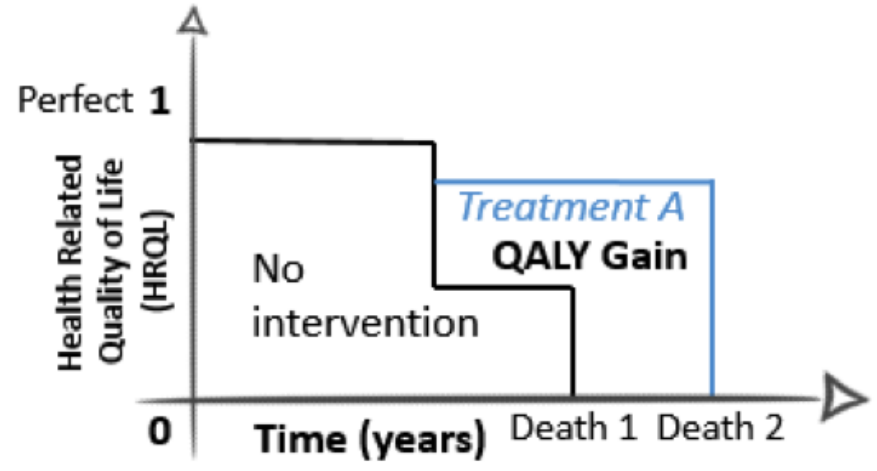

DALY

(Disabilityadjusted life years)
A burden of disease measure based on the number of years lost from premature death, disease, or disability. The loss of one healthy year of life due to death or illness is equal to one DALY. DALYs were developed by the World Bank and World Health Organization in 1993 to both quantify disease and disability burdens globally and set intervention priorities. Instead of a scale of health like QALYs, DALYs are related to a degree of disability for a specific disease or disability from none (0) to death (1) (see diagram below).

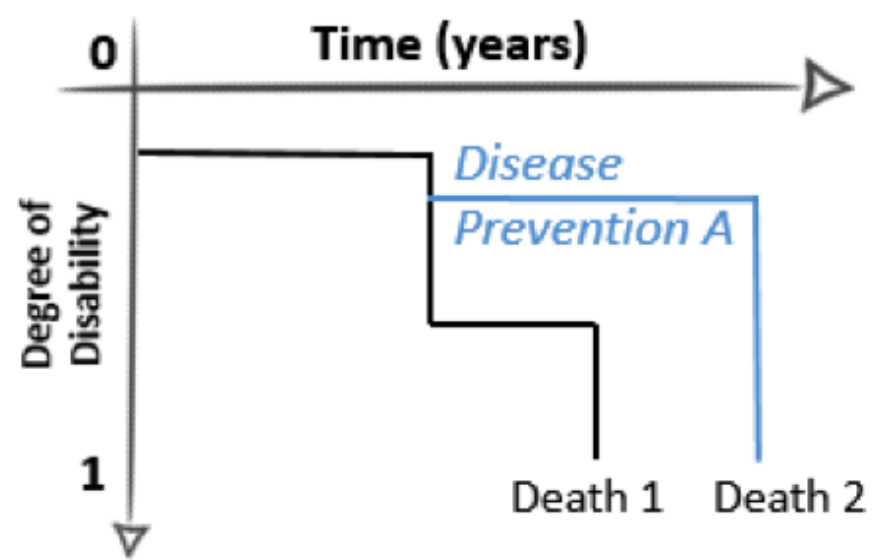

Source: Gold et al., 2002

In general, it is easier to compare DALYs across the world than QALYs. This is because DALYs are based on specific diseases as opposed to QALYs that are based on self-assessments of health that may vary by region and culture (Gold et al., 2002). According to the WHO (2012a), 842,000 annual deaths $(1.5 \%$ of global disease burden in DALYs) from diarrhea were attributed to inadequate water, sanitation, and health. Overall, WASH and water resource management improvements could reduce $10 \%$ of DALYs as inadequate WASH is also associated with malnutrition, malaria, intestinal nematode infections, trachoma, schistosomiasis and other infectious diseases (WHO, 2012a).
In regards to QALYs, side effects from therapies or interventions can be quantified. This is not possible with DALYs. Additionally, it is more common to see economic valuations of QALYs than DALYs. For example, insurance companies may put a limit of $\$ 50,000$ per QALY gain in the U.S. and 30,000 pounds in the U.K. (Shillcutt et al., 2009). However, those costs are outdated and when adjusted for inflation should be more than twice those values. The value of a QALY will also depend on the economic capability of each country (Shillcutt et al., 2009). Concerning DALYs, the World Bank specified a 150 USD per DALY averted as an attractive investment for a project and 25 USD as highly 
attractive in 1993.

For both QALYs and DALYS, there have been ethical and equitable criticisms. Thus, there are needed improvements for both measurements particularly to attain the SDGs by 2030 that not only aim to improve the most livelihoods but also aim for equality and support of women and vulnerable populations. For example, many in the health care industry and governments use HALYs to calculate the most efficient health interventions to maximize the best health of an entire population which may disadvantage disabled, elderly, vulnerable, and low-income populations (Gold et al., 2002). QALYs have been criticized for placing preference on treatments for younger populations. It is more difficult and expensive to obtain one QALY for an older person than a younger person as the health related quality of life index is generally lower for elder populations (Gold et al., 2002; Pettitt et al., 2016). Furthermore, the WHO placed age-weighting on DALYs and has been criticized for favoring the health of adolescent and middle-aged populations, or "productive" ages, over children and the elderly (Gold et al., 2002). Both using QALYs and DALYs to quantify health impacts make it difficult to justify health prioritization of people with rare or debilitating diseases or disabilities that are expensive and difficult to treat. Gold et al. (2002) and others have called to incorporate more "societal value" into analyzing HALYs and not solely cost-effectiveness as well as a better way to directly compare and integrate QALYs and DALYs.
Furthermore, related to the importance of sanitation, the WHO and other researchers should calculate DALYs prevented through sanitation alone (not packaged together in WASH although they are closely linked) as well as the impact on QALYs. These calculations may further prove the importance of sanitation and lead to more investments as opposed to an unequal emphasis on water interventions.

\subsection{The Economic Value of Sanitation}

Although sanitation infrastructure can be expensive, the return on investment and job creation is documented as being much greater. Also, the lack of sanitation is known to impart large costs and job losses to industrial, health, agricultural, and tourism sectors. For example, an evaluation for the World Health Organization (WHO) estimated a 3-34 USD return on every dollar investment in water and sanitation depending on the technology and region (Hutton and Haller, 2004). Additionally, the OECD (2011) cited that there is a 7 to 1 benefit-to-cost ratio by providing basic water and sanitation in developing countries. Furthermore, the 2016 United Nation's World Water Development Report on Water and Jobs (WWDR, 2016) calculated that $42 \%$ or the world's jobs (1.35 billion) are heavily dependent on water and 36\% (1.15 million jobs) are moderately dependent on water (see Figure 6). Furthermore, many of these jobs rely on clean surface water that can be protected by proper sanitation.

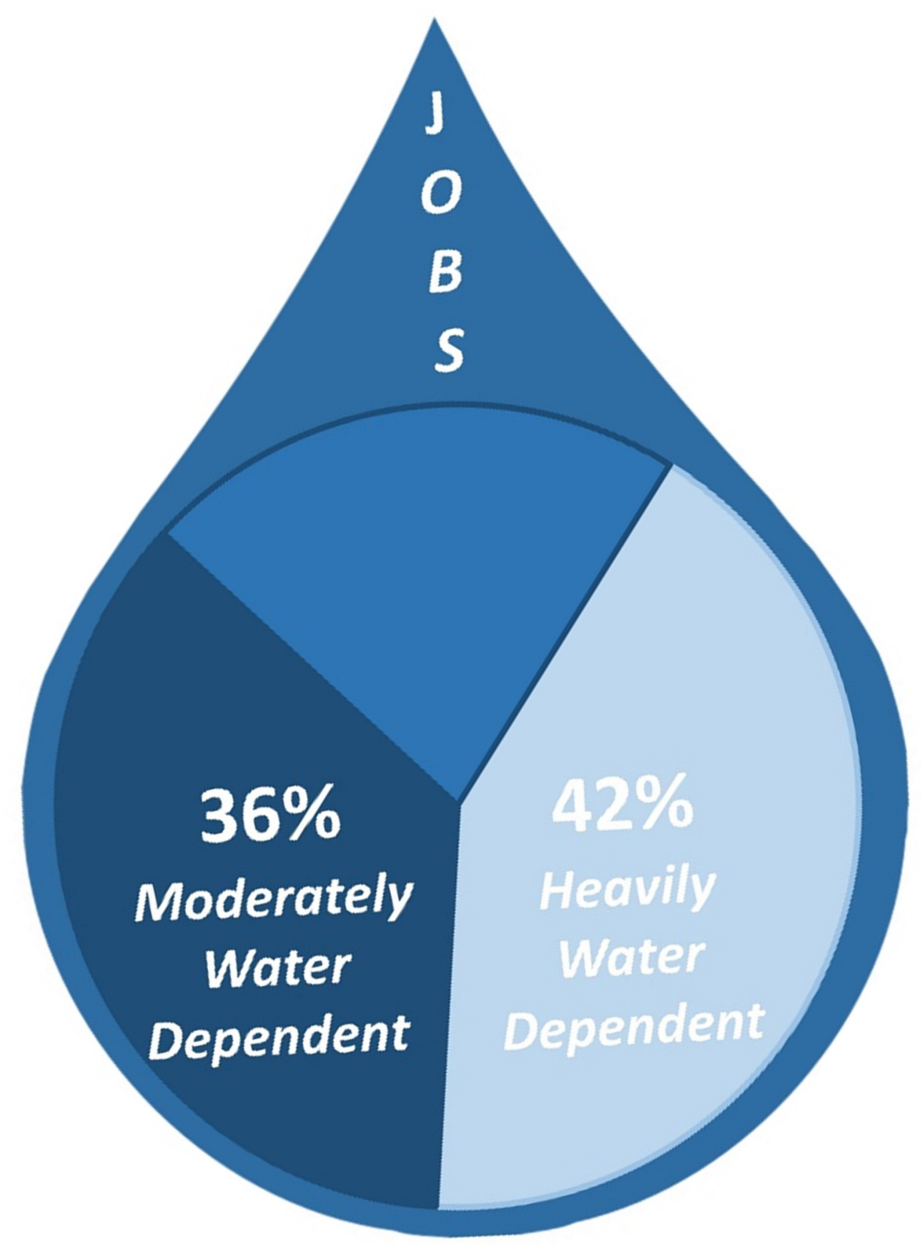

Figure 6. Percentage of the world's jobs that are heavily and moderately water dependent (created from WWDR (2016) statistics). 
Investing in sanitation not only has positive economic returns, creates jobs, and contributes to a vibrant economy but not investing or 'inaction' in sanitation provision can have a highly negative impact on a nation's economy. For example, the 1991 cholera epidemic in Peru cost the nation an estimated 700 million USD including losses in tourism and food products (WWDR, 2016). Furthermore, 17\% of the 2.3 million work-related deaths each year are attributed to lack of clean water and sanitation and poor hygiene (ILO, 2003; WWDR, 2016). Poor sanitation also leads to illness associated with work and school absenteeism and decreased productivity. In fact, inadequate WASH is estimated to result in approximately 260 billion USD economic loss each year globally (WHO, 2012b). Polluted surface water can also deter potential tourists and contaminate agricultural products if used for irrigation, making them more difficult for export (WWDR, 2016). Also there are opportunities for the industry to innovate low-cost sanitation technologies to take advantage of the huge market (billions of people that need access).

\subsection{Appropriate and Low-Cost Sanitation}

Sanitation does not necessarily have to be implemented on a large scale and use expensive and complex systems connected to energy and chemical intensive unit processes. There are many lower cost options such as On-site Sanitation Systems including Ventilated-Improved Pit (VIP), traditional, dry desiccating, and composting toilets, septic systems, and natural systems. Also lower cost sanitation systems are being developed and implemented that have smaller diameter pipes placed in shallower trenches (WWDR, 2017). More decentralized systems and package plants may be a lower cost option than the traditional and large centralized systems and they offer greater opportunity for localized resource recovery of energy, water, and nutrients (WWDR, 2017). Furthermore, less mechanically intensive sanitation technologies such as Anaerobic Reactors and Media Filters and natural treatment systems such as Waste Stabilization Ponds and Constructed Wetlands can have lower capital and operating costs and may be easier to operate than Activated Sludge Systems while having similar or more effective ability to remove pathogens. However, all these lower cost sanitation systems still require important maintenance that is not always factored into project design and implementation.

\subsection{Potential of Resource Recovery and Reuse that is Linked to Safe Sanitation}

SDG 6 has Target 6.3 to substantially increase recycling and safe reuse of wastewater. Furthermore, SDG 12 has a Target 12.2 to achieve the sustainable management and efficient use of natural resources. Wastewater is now viewed by many as not a waste, but a resource that contains energy, water, nutrients (i.e. fertilizer), and possibly valuable organic chemicals (Guest et al., 2009). Furthermore, development, construction, research, and monitoring of resource recovery technologies that are linked with sanitation provision is also expected to create new markets and employment and generate revenue further adding to the value of sanitation (WWDR, 2017). First, energy can be recovered from wastewater through anaerobic digestion which in the form of biogas can be used directly for cooking or heating, or converted into electricity. Anaerobic reactors and anaerobic digestion of sludge can be used to treat wastewater, stabilize sludge, and remove pathogens that are susceptible to microbial and thermal degradation. However, if improperly managed, production of methane from the anaerobic process can contribute considerably to climate change because methane has a much greater greenhouse gas potential than carbon dioxide (Bruun et al., 2014). Next, the largest component of wastewater is water, on average over 99\% (WWDR, 2017). Already, it is estimated that untreated wastewater irrigates between four and 20 million hectares of land worldwide (Jiménez Cisneros and Asano, 2008; Drechsel et al., 2010). However, this is not advised without proper treatment and design because if unsafely reclaimed (see Wastewater Reuse chapter), irrigation with untreated wastewater could expose individuals to pathogens.

Besides water and energy, important nutrients such as nitrogen and phosphorus can be recovered from wastewater. Nitrogen and phosphorus are key components of fertilizers that require mining and energy intensive processes to synthetically produce. Production of nitrogen for fertilizers is energy intensive and has resulted in large imbalances of reactive nitrogen in waterways. Approximately $22 \%$ of the entire global phosphorus demand could be met by phosphorus from human urine and feces (Mihelcic et al., 2011). With rising population and stress on finite and strategically critical mineral resources for production of food and other products, wastewater should be viewed as an important source of phosphorus, nitrogen, and potassium (WWDR, 2017). Resource recovery initiatives can occur at the household or building scale and can include use of established sanitation technologies such as composting and dry desiccating toilets, urine diversion, and anaerobic reactors or newer technologies. For example, an anaerobic membrane bioreactor has been proposed for provision of sanitation that could be linked to local food production (Bair et al., 2016).

Reuse of treated wastewater for food production (Verbyla et al., 2013), valuable nutrients found in human urine and feces (Cordell et al., 2011) and safe management of faecal sludge (Strande et al., 2014) all provide examples of the potential for integrating principles of resource recovery with sanitation provision. There is thus a large untapped potential to integrate innovative resource recovery strategies with sanitation provision in developing regions like sub-Saharan Africa and Asia that have large populations currently unserved by basic sanitation. In contrast, other regions of the world that already have existing sanitation coverage need to determine how to retrofit existing collection and treatment systems to recover valuable resources. 


\section{References}

Bair, R.A., Ozcan, O.O., Calabria, J.L., Dick, G.H. and Yeh, D.H. (2016). Feasibility of anaerobic membrane bioreactor (AnMBR) for onsite sanitation and resource recovery (nutrients, energy, and water) in urban slums. Water Science and Technology. 72, pp. 1543-1551.

Bond, T., Roma, E., Foxon, K.M., Templeton, M.R. and Buckley, C.A. (2013). Ancient water and sanitation systems applicability for the contemporary urban developing world. Water Science and Technology. 67, pp. 935-941. doi: 10.2166/wst.2013.628.

Bruun, S., L. Jensen, S., V. Vu, T.Khanh and Sommer, S. (2014). Small-scale household biogas digesters: An option for global warming mitigation or a potential climate bomb?. Renewable and Sustainable Energy Reviews. 33, pp. 736-741. doi: 10.1016/j.rser.2014.02.033.

Clasen, T., Boisson, S., Routray, P., Torondel, B., Bell, M., Cumming, O. et al. (2014). Effectiveness of a rural sanitation programme on diarrhoea, soil-transmitted helminth infection, and child malnutrition in Odisha, India : a clusterrandomised trial. The Lancet Global Health. 2, Clasen et al. Open Access article distributed under the terms of CC BY-NCND. pp. e645-e653. doi: 10.1016/S2214-109X(14)70307-9.

Cordell, D., Rosemarin, A., Schröder, J.J. and Smit, A.L. (2011). Towards global phosphorus security: A systems framework for phosphorus recovery and reuse. Chemosphere. 84, pp. 747-758.

Drechsel, P. and Evans, A.E.V. (2010). Wastewater use in irrigated agricultureitle. Irrigated and Drainage Systems. 24, pp. 1-3. doi: 10.1007/s10795-010-9095-5.

Feachem, R.G., Bradley, D.J., Garelick, H. and Mara, D.D. (1983). Sanitation and Disease: Health Aspects of Excreta and Wastewater Management. World Bank. John Wiley and Sons. New York.

Feachem, R.G., Bradley, D.J., Garelick, H. and Mara, D.D. (1981). Appropriate Technology for Water Supply and Sanitation: Health Aspects of Excreta and Sullage Management- A State-of-the-Art Review. World Bank.

Ferriman, A. (2007). BMJ readers choose the "sanitary revolution" as greatest medical advance since 1840. British Medical Journal. 334, pp. 111.

Gold, M.R., Stevenson, D. and Fryback, D.G. (2002). Halys and Qalys and Dalys, Oh my: Similarities and Differences in Summary Measures of Population Health. Annual Review of Public Health. 23, pp. 115-134. doi: 10.1146/annurev.publhealth.23.100901.140513.

Graham, J.P. and Polizzotto, M.L. (2013). Pit Latrines and Their Impacts on Groundwater Quality : A Systematic Review. 121 , pp. 521-530.

The Global Development Research Center (GRDC) (2017). International Decade for Clean Drinking Water, 1981-1990.

Guerrant, R.I., DeBoer, M.D., Moore, S.R., Scharf, R.J. and Lima, A.A.M. (2013). The impoverished gut- a triple burden of diarrhea, stunting, and chronic disease. Nature Reviews. Gastroenterology and Hepatology. 10, pp. 220-229. doi: 10.1038/nrgastro.2012.239. 
Guest, J.S., Skerlos, S.J., Barnard, J.L., Beck, M.B., Daigger, G.T., Hilger, H. et al. (2009). A new planning and design paradigm to achieve sustainable resource recovery from wastewater. Environmental Science and Technology. 43, pp. 126-130. doi: 10.1021/es9010515.

Harris, M., Alzua, M.L., Osbert, N. and Pickering, A. (2017). Community-Level Sanitation Coverage More Strongly Associated with Child Growth and Household Drinking Water Quality than Access to a Private Toilet in Rural Mali. Environmental Science and Technology. doi: 10.1021/acs.est.7b00178.

Hutton, G. and Haller, L. (2004). Evaluation of the Costs and Benefits of Water and Sanitation Improvements at the Global Level. World Health Organization (WHO). Geneva, Switzerland.

International Labor Organization (ILO) (2003). Safety in Numbers: Pointers for a Global Safety Culture at Work. ILO. Geneva, Switzerland.

International Year of Sanitation (IYS) (2008). International Year of Sanitation.

Jiménez-Cisneros, B. (2008). Unplanned reuse of wastewater for human consumption: The Tula Valley, Mexico. Water Reuse: An International Survey of Current Practice, Issues and Needs. Scientific ed. (Jiménez-Cisneros, B. and Asano, T., ed.). IWA Publishing. London.

Johnson, S. (2006). The Ghost Map: The Story of London's Most Terrifying Epidemic-and How it Changed Science, Cities, and the Modern World. (Books, R., ed.).

Levy, K., Woster, A.P., Goldstein, R.S. and Carlton, E. (2016). Untangling the Impacts of Climate Change on Waterborne Diseases: a Systematic Review of Relationships between Diarrheal Diseases and Temperature, Rainfall, Flooding, and Drought. Environmental Science and Technology. 50, pp. 4905-4922. doi: 10.1021/acs.est.5b06186.

Water for Life (2015). International Decade for Action 'Water for Life' 2005-2015.

Mellor, J.E., Levy, K., Zimmerman, J., Elliot, M., Bartram, J., Carlton, E. et al. (2016). Planning for climate change: The need for mechanistic systems-based approaches to study climate change impacts on diarrheal diseases. Science of the Total Environment. 548, pp. 82-90. doi: 10.1016/j.scitotenv.2015.12.087.

Mihelcic, J.R., Fry, L.M., Myre, E.A., Phillips, L.D. and Barkdoll, B.D. (2009). Field Guide to Environmental Engineering for Development Workers: Water, Sanitation, and Indoor Air. American Society of Civil Engineers. American Society of Civil Engineers. Reston, VA.

Mihelcic, J.R., Fry, L.M. and Shaw, R. (2011). Global potential of phosphorus recovery from human urine and feces. Chemosphere. 84, pp. 832-839.

Mihelcic, J.R., Naughton, C.C., Verbyla, M.E., Zhang, Q., Oakley, S.M., Schweitzer, R.W. et al. (2017). The Grandest Challenge of All: The Role of Environmental Engineering to Achieve Sustainability in the World's Developing Regions. Environmental Engineering Science. 34, pp. 16-41. 
Mitchell, P.D. (2017). Human parasites in the Roman World: Health consequences of conquering an empire. Parasitology. 144, pp. 48-58. doi: 10.1017/S0031182015001651.

Organisation for Economic Co-operation Development (OECD) (2011). Benefits of Investing in Water and Sanitation: An OECD Perspective. OECD Publishing. Paris, France. doi: 10.1787/9789264100817-en.

Pettitt, D.A., Raza, S., Naughton, B., Roscoe, A., Ramakrishnan, A., Ali, A. et al. (2016). Stem Cell Research and Therapy The Limitations of QALY: A Literature Review. Journal of Stem cell Research and Therapy. 6, pp. 1000334. doi: 10.4172/2157-7633.1000334.

Prüss-Ustün, A., Bartram, J., Clasen, T., Colford, J.M., Cumming, O., Curtis, V. et al. (2014). Burden of disease from inadequate water, sanitation and hygiene in low- and middle-income settings: A retrospective analysis of data from 145 countries. 19, pp. 894-905. doi: 10.1111/tmi.12329.

Sato, T., Qadir, M., Yamamoto, S., Endo, T. and Zahoor, A. (2013). Global, regional, and country level need for data on wastewater generation, treatment, and use. Agricutlural Water Management. 130, Elsevier B.V. pp. 1-13.

Schmidt, W.-.P. (2014). The elusive effect of water and sanitation on the global burden of disease. 19, pp. 522-527. doi: 10.1111/tmi.12286.

Shillcutt, S.D., Walker, D.G., Goodman, C.A. and Mills, A.J. (2009). Cost-Effectiveness in Low- and Middle-Income Countries: A Review of the Debates Surrounding Decision Rules. Pharmacoeconomics. 27, pp. 903-917.

Strande, L., Ronteltap, M. and Brdjanovic, D. (2014). Faecal Sludge Management: Systems Approach for Implementation and Operation. IWA Publishing. London, U.K.

Strunz, E.C., Addiss, D.G., Stocks, M.E., Ogden, S. and Freeman, M.C. (2014). Water, Sanitation, Hygiene, and SoilTransmitted Helminth Infection: A Systematic Review and Meta-Analysis. PLOS Medicine. 11, pp. e1001620. doi: 10.1371/journal.pmed.1001620.

UN-Water (2015). Wastewater Management: A UN-Water Analytical Brief.

UN DESA (2011). World Urbanization Prospects: The 2011 Revision. United Nations. New York.

UNEP (2016). A Snapshot of the World's Water Quality: Towards a Global Assessment. UNEP. Nairobi.

UNESCAP/UN-Habitat/AIT (United Nations Economic Social Commission for Asia the Pacific/United Nations Human Settlements Programme/Asian Institute of Technology) (2015). Policy Guidance Manual on Wastewater Management with a Special Emphasis on Decentralized Wastewater Treatment Systems (DEWATS). UN/AIT.

United Nations (2015). Millennium Development Goals. United Nations.

United Nations (2010). Resolution 64/292: The Human Right to water and sanitation. 
Verbyla, M.E., Oakley, S.M. and Mihelcic, J.R. (2013). Wastewater infrastructure for small cities in an urbanizing world: Integrating protection of human health and the environment with resource recovery and food security. Environmental Science and Technology. 47, pp. 3598-3605.

WHO (2017). Diarrhoeal Disease: Fact Sheet. World Health Organization (WHO). Geneva, Switzerland.

WHO (2017). Safely managed drinking water- thematic report on drinking water 2017. World Health Organization. Geneva, Switzerland.

WHO (2016). Children: reducing mortality.

WHO (2014). Investing in Water and Sanitation: Increasing Access, Reducing Inequalities. Global Analysis and Assessment of Sanitation and Drinking-Water (GLAAS) Report. WHO. Geneva, Switzerland.

WHO (2012). Mortality and burden of disease from water and sanitation. Global Health Observatory (GHO) data.

WHO (2012). Global Costs and Benefits of Drinking-water Supply and Sanitation Interventions to Reach the MDG Target and Universal Coverage. WHO. Geneva, Switzerland.

WHO/UNICEF JMP (2015). WHO/UNICEF Joint Monitoring Program (JMP) for Water Supply and Sanitation.

WHO/UNICEF Joint Monitoring Program(JMP) (2017). WASH in the 2030 Agenda: New Indicators for water, sanitation and hygiene.

Wolf, J., Prüss-Ustün, A., Cumming, O., Bartram, J., Bonjour, S., Cairncross, S. et al. (2014). Assessing the impact of drinking water and sanitation on diarrhoeal disease in low- and middle-income settings : systematic review and metaregression. 19, pp. 928-942. doi: 10.1111/tmi.12331.

World Water Development Report (WWDR) (2017). Wastewater: The Untapped Resource. United Nations Educational, Scientific and Cultural Organization (UNESCO). Paris, France.

World Water Development Report (WWDR) (2016). Water and Jobs. United Nations Educational, Scientific and Cultural Organization (UNESCO). Paris, France.

Zhang, Q., Prouty, C., Zimmerman, J.B. and Mihelcic, J.R. (2016). More than Target 6.3 : A Systems Approach to Rethinking Sustainable Development Goals in a Resource-Scarce World. Engineering. 2, Elsevier LTD on behalf of Chinese Academy of Engineering and Higher Education Press Limited Company. pp. 481-489. doi: 10.1016/J.ENG.2016.04.010. 